\title{
PUNTAS PEDUNCULADAS PEQUEÑAS: VARIABILIDAD MORFOMÉTRICA Y DISTRIBUCIÓN ESPACIAL EN EL NORTE DE LA PROVINCIA DEL CHUBUT (PATAGONIA ARGENTINA) DURANTE EL HOLOCENO TARDÍO
}

\author{
SMALL STEMMED POINTS: MORPHOMETRIC VARIABILITY AND SPATIAL \\ DISTRIBUTION IN THE NORTH OF CHUBUT PROVINCE (ARGENTINE \\ PATAGONIA) DURING THE LATE HOLOCENE
}

\author{
Anahí Banegas ${ }^{1}$, María Soledad Goye y Julieta Gómez Otero ${ }^{1,3}$
}

\begin{abstract}
Se presentan los resultados del análisis morfométrico y técnico de 103 puntas líticas pedunculadas de tamaño pequeño del norte de la provincia del Chubut (Patagonia argentina). Fueron halladas en tres ambientes próximos, pero ecológicamente diferenciados: la costa, el valle medio e inferior del Río Chubut y la meseta centro-norte. Los ejemplares provienen de muestreos arqueológicos y de una colección particular. El objetivo es reconocer tendencias y explorar su relación con decisiones tecnológicas y con la circulación de materias primas, objetos, diseños e información entre distintos grupos. Se registró alta diversidad morfológica intra e interareal, pero predominio de tres subtipos de puntas de limbo triangular recto o ligeramente convexo, aletas salientes o entrantes y pedúnculos diferenciados de bordes rectos y bases cóncavas. Dos de ellos no fueron identificados en la bibliografía disponible para otras partes de Patagonia. Se realizaron análisis estadísticos -ANOVA y ACPsobre las variables métricas del pedúnculo que no arrojaron diferencias significativas. Se comprobó la utilización mayoritaria de calcedonias, obsidianas y xilópalos de fuentes espacialmente circunscritas. Los resultados indican circulación de diseños y materias primas entre las tres áreas, lo que avala distintos modelos de intensificación de los contactos en el centro y norte de Patagonia hacia el Holoceno Tardío final.
\end{abstract}

Palabras claves: puntas de proyectil pedunculadas pequeñas, variabilidad morfométrica, Holoceno Tardío, Patagonia.

The results of morphometric and technical analyses of 103 small stemmed projectile points from the north of Chubut province (Patagonia, Argentina) are presented. These artifacts were collected in three ecologically differentiated but adjacent environments: the maritime coast, the middle and the lower valley of the Chubut River, and the northern-central plateau. The specimens were obtained during archaeological research and from a private collection. The goal of this research is to identify trends and to explore their relationship with technological-based decisions and the circulation of raw materials, objects, designs, and information among different groups. Although highly intra and interarea morphological diversity is recorded, three subtypes predominate: straight or slightly convex triangular edges, stems with straight edges and concave bases. Two of these subtypes have not yet been identified in the archaeological literature from other parts of Patagonia. Statistical analyses ANOVA and PCA, carried out on the metric attributes of the stem, did not show significant differences. Chalcedony, obsidian, and fossilized wood from spatially circumscribed sources were proven to be the most frequent raw materials among the three areas, supporting different models of intensification of exchanges in central and northern Patagonia by the end of late Holocene.

Key words: Small stemmed projectile points, morphometric variability, Late Holocene, Patagonia.

A través del análisis de variables de forma y tamaño de las puntas de proyectil la arqueología abordó el estudio de diversos aspectos de las poblaciones humanas, entre ellos, las estrategias de subsistencia, los sistemas técnicos e incluso las relaciones sociales intra e intergrupales (Banegas et al. 2014; Bettinger y Eerkens 1999; Buchanan et al. 2007; Charlín y González José 2012; Franco et al. 2009; Nelson 1991; Ratto 2003;

\footnotetext{
${ }^{1}$ Instituto de Diversidad y Evolución Austral (IDEAus- CONICET). Puerto Madryn, Chubut, Argentina. banegas.anahi@yahoo.com.ar ${ }^{2}$ Universidad del Chubut, Puerto Madryn, Chubut, Argentina. msgoye@yahoo.com.ar

${ }^{3}$ Facultad de Ciencias Sociales y Humanidades, Universidad Nacional de la Patagonia "San Juan Bosco", sede Trelew, Argentina. julietagomezotero@yahoo.com.ar
} 
Thomas 1978; Wiessner 1983). Los trabajos pioneros se focalizaron en identificar tipos morfológicos que fueron considerados "fósiles guía", indicadores de complejos culturales espacialmente acotados (Knecht 1997). Por su parte, la corriente difusionista sostuvo que la presencia y la propagación espacial de los diseños señalaban las áreas de interacción entre grupos, y que los préstamos culturales y la aculturación eran los mecanismos responsables de la incorporación de un nuevo rasgo (Knecht 1997). Estos abordajes netamente tipológicos tuvieron fuertes críticas. En este sentido, se señaló que la variabilidad artefactual está influenciada por la forma en que se organiza la tecnología en relación con las actividades realizadas, la movilidad y la subsistencia (Binford 1973, 1979). Por otra parte, dada la dificultad de reconocer su forma original luego de los episodios de mantenimiento de que son objeto a lo largo de su vida, se cuestionó la validez de utilizar la morfología de los instrumentos como indicador cultural o cronológico útil (Dibble 1987; Kuhn 1990; Shott y Weedman 2007; entre otros). A partir de la década de 1990 las corrientes procesuales enfatizaron el rol social de la tecnología, sobre todo a partir de la incorporación del enfoque de la organización tecnológica (Nelson 1991). En consecuencia, la morfología y el diseño de las puntas comenzaron a ser evaluados en función de establecer los límites sociales y étnicos entre distintas poblaciones, explorar decisiones técnicas y tradiciones estilísticas y, a través de ellas, acceder a la territorialidad y la interacción de las poblaciones humanas (Bettinger y Eerkens 1999; Odell y Cowan 1986; Verhart 1990).

En lo que respecta a los estudios sobre puntas líticas en Patagonia argentina, las investigaciones siguieron la misma trayectoria: los primeros estudios se enfocaron en caracterizar su morfología y tamaño para distinguir tipos morfológicos y vincularlos con secuencias cronológicas y culturales (Aschero 1983, 1988; Crivelli Montero et al. 1993; Fernández 1988-90; Gradin 1980; entre otros). Trabajos posteriores se dedicaron a explorar los procesos de manufactura (Nami 1997), las técnicas de caza y los sistemas de armas (Aschero y Martínez 2001; Banegas et al. 2014; Charlin y González-José 2012; Ratto 2003; entre otros).

De acuerdo con estos estudios, las puntas -tanto pedunculadas como apedunculadas- muestran variedad de diseños y materias primas. Las apedunculadas son más frecuentes en latitudes septentrionales (Alberti y Cardillo 2016; Crivelli Montero et al. 1993; Fernández 1988-90; Martínez 2017); las pedunculadas en el centro y el sur (Aschero et al. 1983; Banegas et al. 2014; Bird 1988; Gradin 1980; Franco et al. 2009; Franco et al. 2010). Las más pequeñas fueron halladas en contextos del Holoceno Tardío final y se las vinculó con el uso del arco y la flecha (Aschero 1988; Gradin 1980).

En este trabajo se analiza comparativamente la variabilidad morfológica y métrica de una muestra de 103 cabezales líticos hallados en tres ambientes próximos, pero ecológicamente diferenciados del norte de la provincia de Chubut: (1) la costa, (2) el valle medio e inferior del Río Chubut y (3) la meseta centronorte. Desde el enfoque de la Organización Tecnológica (Nelson 1991), se exploran tendencias y se las discute en función de decisiones tecnológicas y circulación de materias primas, objetos, diseños e información entre distintos grupos.

\section{Antecedentes}

\section{Caracterización sintética de la oferta de recursos líticos y antecedentes arqueológicos generales}

Las tres áreas comparten un clima árido, con temperaturas medias anuales entre $9^{\circ} \mathrm{C}$ en la meseta central y $12-13^{\circ} \mathrm{C}$ en la costa norte y valle inferior. La pluviosidad anual es inferior a $225 \mathrm{~mm}$ anuales, agregándose precipitaciones nivales en la meseta centro-norte (Beeskow et al. 1987). Prevalecen los vientos intensos del cuadrante oeste, aunque los del norte son frecuentes y tienen alto impacto en la costa. La vegetación dominante es la estepa arbustivasubarbustiva y el matorral (Beeskow et al. 1987).

El sector aquí definido como "Costa Norte" (en adelante $\mathrm{CN}$ ) se extiende desde la desembocadura del Arroyo Verde al norte y Bahía Cracker al sur (Figura 1). El paisaje se caracteriza por mesetas que no superan $110 \mathrm{msm}$. La geología del área es bastante simple: predominan las rocas sedimentarias de edad terciaria (Formación Gaiman y Formación Puerto Madryn) y cuaternaria (Rodados Tehuelches y rodados marinos) (Haller 1982). La oferta de materias primas está mayoritariamente dada por las fuentes secundarias de rodados de tamaño guijarro (sensu Bonorino y Teruggi 1952) y diversas litologías (Banegas y Goye 2015; Banegas et al. 2015). Las de mejor calidad para la talla -muy buena- son los basaltos (55\%) y las sílices (18\%). En la zona del Arroyo Verde se encuentran los únicos afloramientos de rocas "duras" del área, representados por la Formación Marifil (Malvicini y Llambías 1974) de edad jurásica, que ofrecen ignimbritas, tobas silíceas y también vetas de calcedonia blanca de muy buena a excelente calidad para la talla (Massaferro y Haller 2000).

El registro arqueológico se distingue por el predominio de sitios de superficie y a cielo abierto en relieves dunarios o al borde de terrazas marinas bajas (Gómez Otero 2006). Estos contextos evidencian alto impacto por procesos postdepositacionales de origen natural (erosión eólica, hídrica, exposición solar, bioturbación, entre otros) y antrópico (urbanización creciente, obras de infraestructura, actividades 
recreativas y coleccionismo) (Gómez Otero 2008). Los estudios realizados señalan que el área fue ocupada desde 7.400 AP por cazadores-recolectores con rangos de acción regular a lo largo del perímetro costero y con dieta mixta (marina-terrestre) (Gómez Otero 2006; Gómez Otero et al. 1999). Los análisis tecnológicos muestran el aprovechamiento intensivo de los rodados locales de sílice y basalto de buena calidad para la talla (Banegas 2016, Banegas y Goye 2015). En muy escasa proporción también se explotaron rocas foráneas como xilópalos (Banegas et al. 2016) y obsidianas de seis fuentes: tres desconocidas y tres conocidas: Telsen (T/SCI), Sacanana (SI) y Pampa del Asador (PDAI) (Stern et al. 2000; Gómez Otero y Stern 2005).

El área denominada "Valle medio e inferior del Río Chubut" (en adelante VCH) comprende una muestra del área suburbana de Rawson (valle inferior) y otras de la localidad Los Altares (valle medio) que forman parte de una colección privada (Figura 1). La geología es diferente en estos dos sectores del valle. En Los Altares, el río presenta un hábito encajonado entre formaciones rocosas y serranías bajas de la Formación Marifil que aportan distintas litologías -ignimbritas, tobas y sílices (Ichazo 1994; Panza et al. 2002); las dos últimas de muy buena calidad para la talla. Por su parte, el tramo final del valle inferior es ancho, meandroso y está labrado sobre sedimentitas del Terciario de la Fomación Gaiman (Haller 1981). Se observa el desarrollo de albardones y también de cordones litorales formados por un mar en regresión (Ichazo 1994). Banegas et al. (2015) determinaron el predominio de basaltos (30\%) y sílices (24\%) de muy buena calidad para la talla. En frecuencias muy bajas (3,6\%) se identificaron calcedonias y xilópalos de calidad excelente. Hacia el oeste del valle, a unos $150 \mathrm{~km}$ lineales de Rawson, existe un bosque petrificado en la zona del Dique Ameghino (Brea et al. 2006), aunque se desconoce la aptitud de esos xilópalos para la talla (Figura 1).

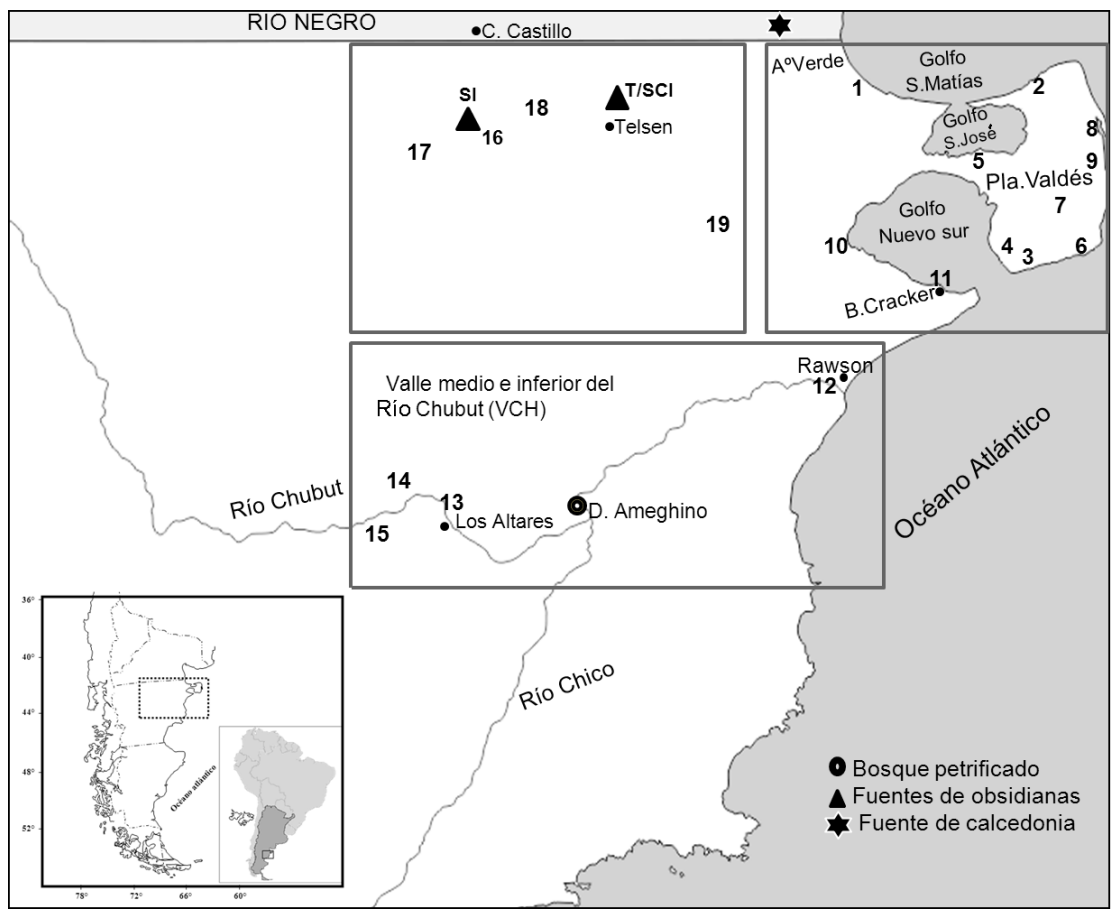

Figura 1. Áreas de estudio: sitios arqueológicos y localización de las fuentes de algunas materias primas líticas. Referencias. Costa Norte: (1) Rincón de Elizalde; (2) El Progreso; (3) La Azucena; (4) Las Ollas; (5) Playa Fracaso; (6) Punta Delgada; (7) Ea. La Laurita; (8) Caleta Valdés; (9) Bajo Norte; (10) El Golfito; (11) Bahía Cracker. Valle inferior y medio del Río Chubut: (12) Rawson; (13) Los Altares; (14) Laguna Bombilla; (15) Cabeza de Buey. Meseta centro-norte: (16) Cerro Chenque; (17) Cañadón de los Fósiles; (18) Sucesión Montenegro; (19) Puesto Arsenio Balbo.

Study areas: archaeological sites and location of some lithic raw materials sources. References: Costa Norte: (1) Rincón de Elizalde; (2) El Progreso; (3) La Azucena; (4) Las Ollas; (5) Playa Fracaso; (6) Punta Delgada; (7) Ea. La Laurita; (8) Caleta Valdés; (9) Bajo Norte; (10) El Golfito; (11) Bahía Cracker. Valle inferior y medio del Río Chubut: (12) Rawson; (13) Los Altares; (14) Laguna Bombilla; (15) Cabeza de Buey. Meseta centro-norte: (16) Cerro Chenque; (17) Cañadón de los Fósiles; (18) Sucesión Montenegro; (19) Puesto Arsenio Balbo. 
Las investigaciones arqueológicas en el valle inferior registraron sitios a cielo abierto en superficie y en estratigrafía, ubicados sobre albardones y terrazas bajas. Los contextos señalan distinta funcionalidad: campamentos-base, campamentos transitorios, talleres líticos, enterratorios individuales y múltiples (Gómez Otero y Dahinten 1997-98; Gómez Otero et al. 2010; entre otros). En su gran mayoría están altamente impactados por los mismos agentes que en la costa norte, aunque en este sector se suman la dinámica del río y la intensa explotación agraria. Las ocupaciones cubren un rango temporal de 3.800 a 200 años AP y corresponden a cazadores-recolectores que hicieron aprovechamiento de recursos terrestres, fluviales y también marinos en la desembocadura (Gómez Otero et al. 2010; Goye y Weiler 2017; Svoboda y Gómez Otero 2015). Los conjuntos artefactuales muestran el aprovechamiento mayoritario de las sílices locales de muy buena calidad y en menor proporción, de rocas alóctonas como xilópalos (Banegas et al. 2016) y obsidianas de tres fuentes: dos desconocidas y la de Sacanana (SI) (Gómez Otero y Stern 2005).

En cuanto al valle medio-inferior, el registro arqueológico permanece poco conocido y hasta la fecha no hay dataciones radiocarbónicas. Se reportaron hallazgos aislados de cerámica (Gómez Otero et al. 1996), sitios de superficie a cielo abierto y estratificados bajo roca (Aschero et al. 1983-85; Schuster y Massaferro 2017). También se describieron pinturas y grabados rupestres (Gradin 1985).

La Meseta centro-norte (en adelante MCN) incluye sitios entre Telsen y Sacanana (Figura 1). El relieve está conformado por serranías bajas en la zona oriental, mientras que la zona occidental alcanza la mayor altura $(1.100 \mathrm{msm})$. La geología de la región es sencilla, afloran las vulcanitas y piroclastitas ácidas de la Formación Marifil (Malvicini y Llambías 1974), también son relevantes los afloramientos de basaltos de la Formación Somún Curá (Ardolino 1981) y las emisiones centrales de piroclastitas y lavas de las sierras de Apas y Telsen. Los principales procesos postdepositacionales naturales que afectan el registro arqueológico son la erosión eólica, hídrica, la bioturbación, la exposición solar y el congelamiento del suelo en invierno. Entre las antrópicas predomina el coleccionismo.

El área se destaca por la alta disponibilidad de materias primas de muy buena a excelente calidad (Gómez Otero et al. 1999). La mayoría proviene de rodados de distinto tamaño de sílices, calcedonias y obsidianas. Con respecto a las obsidianas, existen dos fuentes secundarias separadas entre sí por $150 \mathrm{~km}$ : la de Sacanana (SI) y la de Telsen (T/ SCI) (Gómez Otero y Stern 2005; Stern et al. 2000). Visualmente son muy distintas: SI es negra brillante y de textura lisa; T/SC II varía entre el negro oliva y gris oliva, es brillante, translúcida y a veces presenta bandas más claras (Gómez Otero y Stern 2005:9899). Artefactos de estas dos fuentes aparecieron desde la costa a la cordillera entre las latitudes $41^{\circ} \mathrm{S}$ y $45^{\circ} \mathrm{S}$ (Stern 2018). En Telsen también existe una fuente primaria de calcedonia blanquecina opaca (Gómez Otero et al. 1999) (Figura 1).

Los estudios arqueológicos corresponden a relevamientos de pinturas rupestres (Boschín 2009) y excavaciones en la zona de Cerro Castillo, cerca de Sacanana (Belardi 1996). Se determinaron ocupaciones posteriores a 3.470 años AP (Stern et al. 2000), aprovechamiento de recursos terrestres y estacionalidad centrada en verano (Belardi 1996). Las rocas seleccionadas fueron vulcanitas, tobas silicificadas, calcedonias y obsidianas de las fuentes (SI) y otra desconocida (Gómez Otero y Stern 2005; Ratto y Belardi 1996; Stern et al. 2000). En la localidad arqueológica Sucesión Montenegro, además de pinturas rupestres y materiales en superficie, se registró un enterratorio tipo chenque de dos individuos infantiles datados en 350 años AP (Gómez Otero 2006).

En síntesis, las tres áreas presentan materias primas de muy buena a excelente calidad para la talla, aunque hay diferencias en cuanto a la distribución y frecuencia de las fuentes de calcedonias, xilópalos y obsidianas.

\section{Estudios previos sobre variabilidad morfológica de puntas líticas en el noreste de Chubut}

En el marco del proyecto "Puntas de proyectil y circulación humana en los últimos 12.000 años. Un estudio tecnológico comparativo de puntas de proyectil en Argentina" ", se publicaron dos trabajos sobre cabezales líticos de la provincia del Chubut, específicamente de la costa norte y el valle inferior del Río Chubut (Franco et al. 2010; Gómez Otero et al. 2011) (Figura 1). Uno de ellos analizó la variabilidad morfométrica de 144 puntas halladas en distintos tipos de contextos, en su mayoría de superficie (Gómez Otero et al. 2011). Entre las 110 que tenían el suficiente grado de integridad para identificar tipos y subtipos, se determinó la presencia de cabezales pedunculados $(77 \%)$ y apedunculados (23\%). Todos están confeccionados en rocas de muy buena calidad para la talla, destacándose las silíceas (80\%), seguidas por basaltos, dacitas y andesitas (15\%) y en baja proporción, obsidianas (5\%). Prevalecen los ejemplares de 2 a $4 \mathrm{~cm}$ (61\%) sobre los de 4 a $6 \mathrm{~cm}$ (28\%). Se reconocieron diseños similares a puntas registradas en sitios de diversa antigüedad de otras partes de Patagonia. Por ejemplo, las apedunculadas medianas de limbo triangular (Figura 2: 1a) o foliáceo (Figura 2: 1c) muestran semejanza con ejemplares del Holoceno Temprano a Medio de 
Patagonia septentrional (Crivelli Montero et al. 1993; Fernández 1988-90); central (Cardich et al. 1973; Gradin et al. 1979) y meridional (Bird 1988). Por su parte, las de tamaño pequeño (Figura 2: 1b y 1d) son similares a las típicas del Holoceno Tardío en el norte de Patagonia (Fernández 1988-90; Martínez et al. 2017; Orquera 1987; Prates 2008; entre otros). En cuanto a las pedunculadas, se identificaron 10 subtipos; algunos de ellos presentan rasgos similares a puntas de contextos tardíos del "Complejo Patagoniense" de Patagonia central (Figura 2:2 a-2b) (Aschero et al. 1983, 2006; Gradin 1980), y de las fases "Magallanes IV" (Figura 2:2e-2f) y Magallanes V (Figura 2:2i) de Patagonia meridional (Bird 1988). De todas estas variedades se destacan dos subtipos (Figura 2:2c-2d) que alcanzan el $52 \%$ de la muestra, y que aún no fueron identificados al norte y sur de las áreas aquí tratadas.

El otro trabajo (Franco et al. 2010) se enfocó en el análisis comparativo de puntas pedunculadas de tamaño mediano, conocidas como "Magallanes IV" o "Bird IV" (Bird 1988), de amplia distribución en el extremo meridional de Patagonia. La muestra incluyó ejemplares de 4.000 a 200 años AP provenientes de dos áreas: (a) entre puerto San Julián $\left(49^{\circ} \mathrm{S}\right)$ y el estrecho de Magallanes $\left(52^{\circ} \mathrm{S}\right)$, y (b) el nordeste de Chubut. Si bien se identificaron leves variaciones morfométricas entre las distintas latitudes, estas puntas comparten varios atributos: el ancho y espesor de la raíz, la longitud, el ancho y el espesor del pedúnculo y la razón entre el espesor de la raíz y el espesor del limbo. En este caso, las del nordeste de Chubut (Figura 2:2e-2f) se diferencian por presentar un pedúnculo un poco más angosto. Sobre la base del trabajo de Bettinger y Eerkens (1999), se postuló la existencia de una única población o diseño exitoso que fue replicándose a lo largo de más de tres mil años (Franco et al. 2010). En síntesis, ambos estudios señalan alta variabilidad en diseños y tamaños para el noreste de Chubut, lo que podría vincularse con cambios a través del tiempo, con el uso de diferentes sistemas de armas o técnicas de caza y/o con contactos intrarregionales e interregionales de antigua data (Gómez Otero et al. 2011).

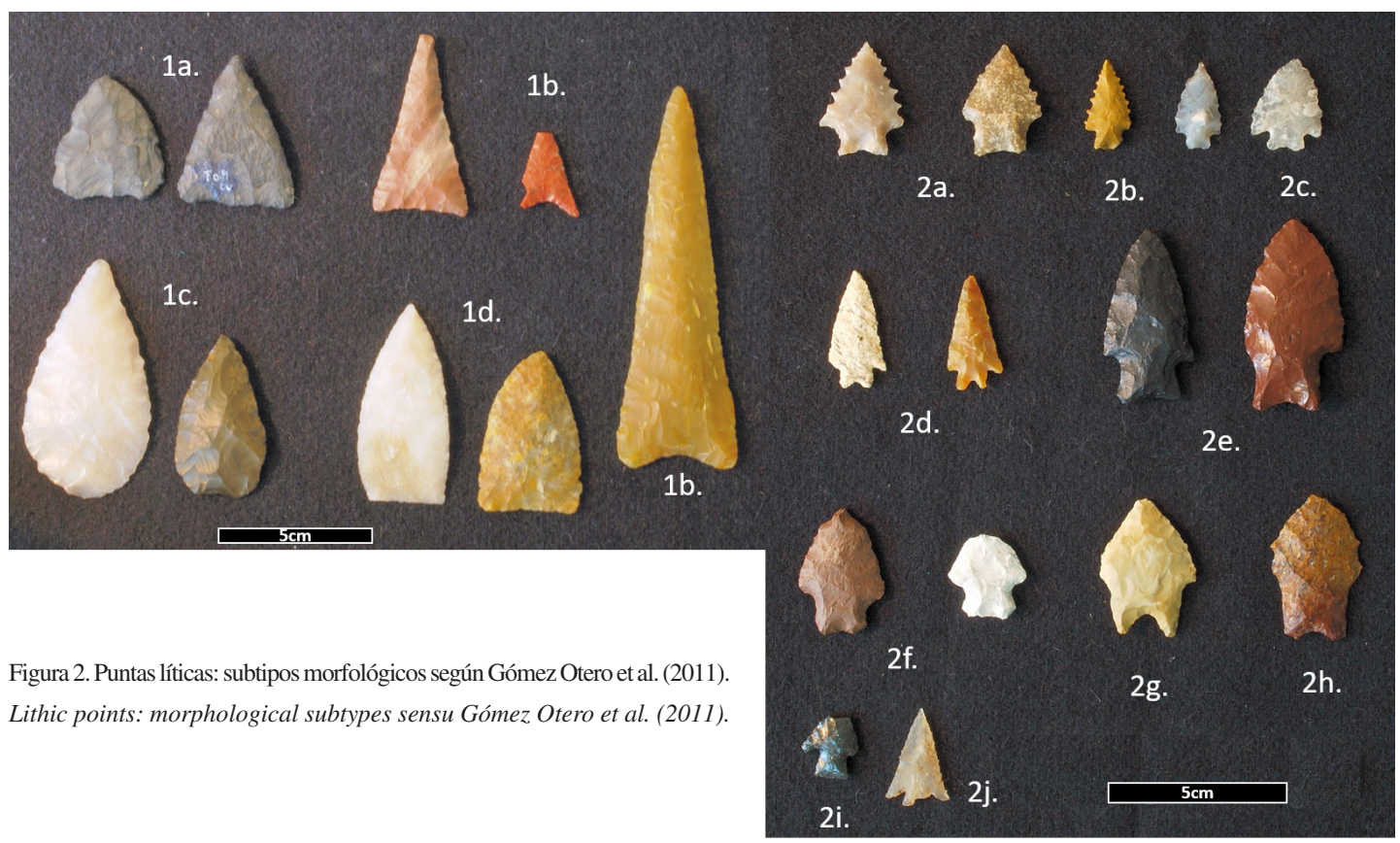




\section{Materiales y Métodos}

Para este trabajo se estudiaron 103 puntas líticas pedunculadas de tamaño pequeño con alto grado de integridad (más del 80\% del total de la pieza) y medidas máximas (reales o proyectadas) iguales o menores a $40 \mathrm{~mm}$ de longitud e iguales o inferiores a $20 \mathrm{~mm}$ de ancho. Este criterio métrico se basó sobre los módulos I (muy pequeños) y II (pequeños) de Bagolini (1968). La procedencia de las 103 puntas se distribuye de la siguiente manera entre las áreas: $\mathrm{CN}(\mathrm{n}=43 ; 42 \%) ; \mathrm{VCH}$ $(\mathrm{n}=23 ; 22 \%)$ y MCN $(\mathrm{n}=37 ; 36 \%)$ (Tabla 1$)$. De las recuperadas en el marco de investigaciones sistemáticas $(n=62), 50$ ejemplares $(80 \%)$ provienen de muestreos en superficie y 12 en estratigrafía (20\%) (Tabla 1). Las 41 piezas restantes (40\%) corresponden a la "Colección Anselmo Cadene", recolectadas en superficie de manera asistemática en el valle medio del Río Chubut y en la meseta centro-norte, desconociéndose otros datos contextuales (Tabla 1). Salvo las puntas de los sitios Las Ollas 1, El Golfito 1 y Rawson, las demás no cuentan con cronologías absolutas por tratarse de hallazgos en superficie (Tabla 1). Los ejemplares no datados fueron atribuidos al Holoceno Tardío según dos criterios: (a) asociación con indicadores cronológicos indirectos de ese período como la presencia de cerámica y placas grabadas, y (b) similitud en tamaño $\mathrm{y}$ forma con puntas halladas en contextos estratificados de otras zonas de la provincia que están fechados y/o presentan asociación con cerámica (Aschero 1975a:1-2
Lámina II; Aschero et al. 1983-85:Figura 5-4; Bellelli 1983:Figura 7 c-d; Aguerre et al. 2018: Figura 4, 1-6; entre otros). Las edades radiocarbónicas más tempranas para la tecnología cerámica en Chubut son: 1.500 años AP en el valle inferior (Gómez Otero et al. 2010), 980 años AP en la costa norte (Gómez Otero et al. 2017) y 1.250 años AP en la meseta centro-sur (Gradin 1980).

La clasificación de las materias primas se realizó con el apoyo de material comparativo de la litoteca del laboratorio de Arqueología del IDEAus. Con respecto a las puntas de obsidiana, no se efectuaron estudios de composición química porque aún no se dispone de la técnica arqueométrica de radiación no destructiva o Fluorescencia de Rayos X. Por lo tanto, la identificación de variedades de esta roca fue macroscópica, considerándose el color, el brillo y la textura (Gómez Otero y Stern 2005). También se tuvo en cuenta la cercanía respecto de los lugares de hallazgo a las fuentes SI o T/SC I y/o la asociación contextual con artefactos ya analizados geoquímicamente (Gómez Otero y Stern 2005; Stern et al. 2000). La calidad para la talla de todas las materias primas se evaluó según los criterios de Franco y Aragón (2004).

\section{Las variables analizadas}

Para distinguir tipos morfológicos se consideraron variables morfométricas y técnicas de acuerdo con la metodología de Aschero (1975b, 1983), de uso generalizado en la arqueología de Patagonia. Este autor define un "tipo

Tabla 1. Distribución de tipos de sitios y proporción de materias primas en cada área.

Distribution of the site types and percentage of raw materials in each area.

\begin{tabular}{|c|c|c|c|c|c|}
\hline $\begin{array}{c}\text { Áreas de estudio y sitios } \\
\text { arqueológicos }\end{array}$ & Contexto de hallazgo & Edad C14 & Asignación cronológica al HT & $\mathrm{N}$ & Referencias \\
\hline \multicolumn{6}{|l|}{$\mathrm{CN}$} \\
\hline Rincón de Elizalde 2 M1 & Superficie & -- & Presencia cerámica & 3 & Gómez Otero 2006 \\
\hline El Progreso 3 M3 & Superficie & -- & Presencia cerámica & 1 & Idem \\
\hline La Azucena 2 & Superficie & --- & Presencia cerámica & 26 & Idem \\
\hline Las Ollas 1 Fogón 1 & Estratificado & $\begin{array}{l}610 \pm 60 \mathrm{AP} \\
640 \pm 60 \mathrm{AP}\end{array}$ & - & 4 & Idem \\
\hline Playa Fracasso M1 & Superficie & -- & Presencia cerámica & 1 & Idem \\
\hline Punta Delgada 3 M1 & Superficie & -- & Presencia cerámica & 1 & Idem \\
\hline Salina Chica 1 M1 & Superficie & -- & Presencia cerámica & 1 & Idem \\
\hline Caleta Valdés TP 6 & Superficie & -- & Presencia cerámica & 1 & Idem \\
\hline Bajo Norte M1 & Superficie & -- & Presencia cerámica & & Idem \\
\hline El Golfito 1 - Ind. 2 & Enterratorio estratificado & $770 \pm 501062-1295 \mathrm{AD}$ & - & 1 & Idem \\
\hline Bahía Cracker & Hallazgo aislado & -- & -- & 1 & Inédita \\
\hline \multicolumn{6}{|l|}{$\mathrm{VCH}$} \\
\hline Rawson & $\begin{array}{c}\text { Enterratorio } \\
\text { múltiple estratificado }\end{array}$ & 270-200 AP & -- & 7 & Gómez Otero y Dahinten 1997 \\
\hline Los Altares & Col. A.C. & -- & -- & 7 & -- \\
\hline Laguna Bombilla & Col. A.C. & -- & -- & 7 & -- \\
\hline Cabeza de Buey & Col. A.C & -- & -- & 2 & -- \\
\hline \multicolumn{6}{|l|}{$\mathrm{MCN}$} \\
\hline Sucesión Montenegro M1 & Superficie & -- & Presencia cerámica & 10 & Gómez Otero y Stern 2005 \\
\hline Cañadón de Los Fósiles M1 & Superficie & -- & -- & 1 & $\begin{array}{c}\text { Stern et al. } \\
2000\end{array}$ \\
\hline Cerro Chenque 2 & Enterratorio en alero & -- & Presencia cerámica & 1 & -- \\
\hline Puesto Arsenio Balbo & Col. A.C. & -- & -- & 25 & \\
\hline
\end{tabular}


morfológico" a partir de la suma descriptiva de los atributos incluidos en la definición de una "serie", un "grupo" y un "subgrupo", que surgieron de la comparación y descripción de cada segmento de piezas individuales (Aschero 1975b:5). Sobre esta base se relevaron las siguientes variables:

Morfológicas. Forma perimetral de cada pieza, forma del borde del limbo, diferenciación de las aletas y del pedúnculo respecto del limbo, forma del borde y de la base del pedúnculo.

Métricas: El largo, ancho y espesor máximos en cada punta completa. En el caso del pedúnculo, el largo máximo, el ancho y espesor de la raíz, el ancho y espesor de la base. Todas las mediciones fueron tomadas con calibre digital Blac Jack DO56/0-150 mm. A los efectos de controlar la variación inter e intra observador, cada punta fue medida dos veces por Banegas y Goye, y los valores resultantes corresponden al promedio entre todas las mediciones.

Tecno-morfológicas. Forma de la sección transversal, serie técnica (que combina las variables ancho y extensión de los lascados sobre las caras), forma y dirección de los lascados, tipo de retoque y tratamiento técnico diferencial de la base del pedúnculo.

Para diferenciar entre diseños básicos y mantenidos o transformados se tuvieron en cuenta los criterios de la caracterización de Martínez (2003) y Aschero et al. (2011). Así, el diseño "básico" es el que conserva su morfología original; el "mantenido" es producto de la reactivación del filo ("rejuvenation" sensu Aschero et al. 2011) para seguir desempeñando la misma función, y "transformado" el que sufre modificaciones morfológicas para cumplir alguna otra función. En todas las muestras se identificaron los distintos tipos de diseños, pero solo en las recuperadas arqueológicamente se exploraron algunos indicadores de reactivación de limbos como la superposición y tipos de lascados, la sección transversal de los ejemplares y la proporción entre el largo total del limbo y el largo del pedúnculo.

El análisis estadístico se aplicó únicamente para las variables métricas del pedúnculo (largo, ancho y espesor de la raíz; ancho y espesor de la base) porque es el sector con mayor grado de integridad de la punta y no suele ser tan frecuentemente reactivado o transformado como el limbo (Banegas etal.2014; Flenniken y Raymond 1986; Francoetal. 2009; Ratto 2003; entre otros). Las medidas de los pedúnculos de cada área se compararon con ANOVA de un factor. Para verificar los supuestos de normalidad y homocedacia se aplicaron las pruebas de Shapiro Wilks-W y la prueba de $\mathrm{F}$ respectivamente (Sokal y Rolf 1995). Para explorar y definir la variación interareal se aplicó el Análisis de Componentes Principales (Manly 1994). En ambas pruebas estadísticas se utilizó el software Past 2.1 (Hammer et al. 2001).

\section{Resultados}

\section{Variables tecno-morfológicas del limbo, aletas y pedúnculo}

En el conjunto de las tres muestras sobresalen los limbos triangulares con proporciones similares de cortos (entre 40 y $52 \%$ ) y alargados (entre 43 y $49 \%$ ). Los cordiformes y lanceolados solo fueron registrados en $\mathrm{MCN}$ (3\%) (Tabla 2). El borde de los limbos es recto en $65 \%$ de las puntas (37\% de ellos aserrados); en segundo lugar se ubican los bordes convexos en MCN (35\%) y CN (21\%) y los cóncavos en VCH (17\%) (Tabla 2). En relación con la forma de las aletas y la diferenciación del pedúnculo, las tres áreas muestran prevalencia de aletas salientes (56 a $38 \%$ ) y entrantes (38 a $30 \%$ ); en orden decreciente les siguen las aletas "en hombro", aunque solo se registraron en $\mathrm{MCN}$ y VCH (24 a $14 \%$ respectivamente) (Tabla 2).

Tabla 2. Características morfológicas del limbo, aletas y de la inserción del pedúnculo.

Morphological features of the blade, notches, and the hafted stem.

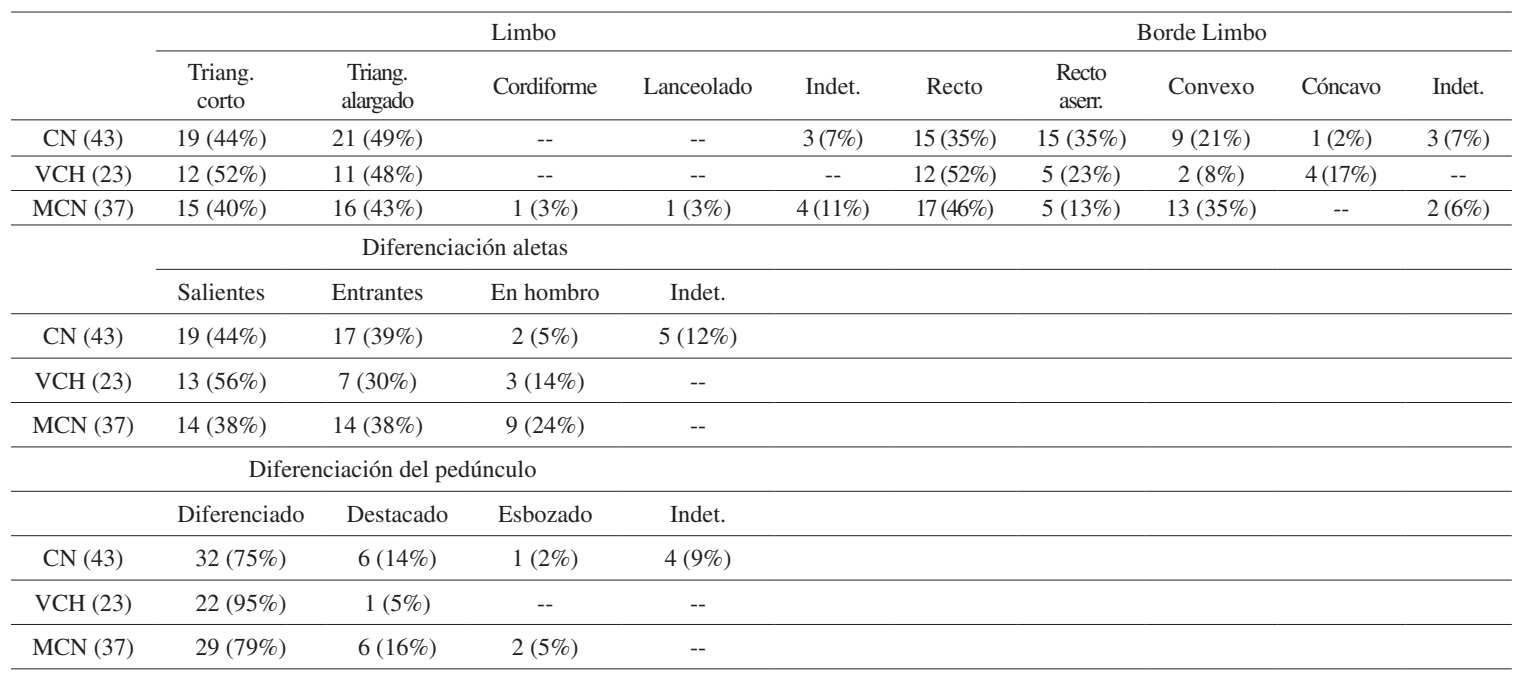


La mayoría de los pedúnculos (95 a 75\%) corresponde a la categoría diferenciado con predominio de los rectos divergentes (52 a 30\%), ubicándose en segundo lugar (32 a 25\%) los rectos paralelos con valores similares en todas las áreas (Tablas 2 y 3 ). Las bases de los pedúnculos son preferentemente cóncavas atenuadas ( 65 a 57\%), aunque también hay cóncavas profundas (39 a 24\%) (Tabla 3). el 2a (26\%), les siguen el $2 \mathrm{~d}$ en $\mathrm{CN}(21 \%)$, el 2a en MCN (24\%) y el 2c y el $2 \mathrm{~d}$ en VCH (17\%, cada uno) (Figura 2).

Los diseños "mantenidos" ocupan el segundo lugar de manera bastante pareja: $16 \%$ en CN, $13 \%$ en VCH y $19 \%$ en MCN. Del total de 62 puntas recuperadas por el equipo, $10(16 \%)$ presentan evidencias de reactivación del limbo. En CN corresponden a los ejemplares LAzu 95 y

Tabla 3. Características morfológicas del borde y de la base del pedúnculo.

Morphological features of the edge and the base of the stem.

\begin{tabular}{ccccccccc}
\hline & \multicolumn{7}{c}{ Borde pedúnculo } \\
\cline { 2 - 8 } & Paralelo recto & $\begin{array}{c}\text { Divergente } \\
\text { recto }\end{array}$ & $\begin{array}{c}\text { Divergente } \\
\text { convexo }\end{array}$ & $\begin{array}{c}\text { Paralelo } \\
\text { cóncavo }\end{array}$ & $\begin{array}{c}\text { Cóncavo } \\
\text { recto }\end{array}$ & $\begin{array}{c}\text { Divergente } \\
\text { cóncavo }\end{array}$ & Convexo & Indet. \\
\hline $\mathrm{CN}(43)$ & $11(25 \%)$ & $13(30 \%)$ & $9(21 \%)$ & $3(7 \%)$ & $2(5 \%)$ & $2(5 \%)$ & $1(2 \%)$ & $2(5 \%)$ \\
\hline $\mathrm{VCH}(27)$ & $6(26 \%)$ & $12(52 \%)$ & $2(9 \%)$ & $1(4 \%)$ & -- & -- & -- & $2(9 \%)$ \\
\hline MI (37) & $12(32 \%)$ & $13(35 \%)$ & $8(22 \%)$ & $2(5 \%)$ & $1(3 \%)$ & $1(3 \%)$ & -- & -- \\
\hline \multicolumn{7}{c}{ Base pedúnculo } \\
\cline { 2 - 8 } & Recto & $\begin{array}{c}\text { Cóncavo } \\
\text { atenuado }\end{array}$ & $\begin{array}{c}\text { Cóncavo } \\
\text { profundo }\end{array}$ & Indet. \\
\hline $\mathrm{CN}(43)$ & $1(2 \%)$ & $25(58 \%)$ & $14(33 \%)$ & $3(7 \%)$ & & \\
\hline $\mathrm{VCH}(27)$ & -- & $13(57 \%)$ & $9(39 \%)$ & $1(4 \%)$ \\
\hline $\mathrm{MCN}(37)$ & $3(8 \%)$ & $24(65 \%)$ & $9(24 \%)$ & $1(3 \%)$ \\
\hline
\end{tabular}

Prevalecen las secciones biconvexas simétricas ( 52 a $31 \%$ ) seguidas por las plano-convexas (36 a 33\%). Sobresale la formatización mediante microrretoque (profundo entre 52 y $42 \%$; marginal entre 32 y $22 \%$ ), preferentemente irregular (más de $35 \%$ ). En el tratamiento de las bases predomina el lascado simple no laminar: en CN (70\%), en VCH (52\%) y en MCN (73\%). El acanalado solo fue significativo en MCN (16\%), mientras que dos puntas -una de $\mathrm{CN}$ y otra de $\mathrm{MCN}$ - fueron adelgazadas por retoque.

En el conjunto total de las tres áreas prevalecen los diseños básicos: en CNalcanzan el $72 \%(\mathrm{n}=31)$, en $\mathrm{VCH}$ el $61 \%(n=14)$ y en $\mathrm{MCN}$ el $41 \%$ ( $\mathrm{n}=15)$. Se observaron coincidencias con tres subtipos pedunculados definidos por Gómez Otero et al. (2011): el 2a (17,4\%), el 2c $(41,7 \%)$ y el $2 \mathrm{~d}(15,5 \%)$. El subtipo $2 \mathrm{a}$ se caracteriza por un limbo triangular corto y recto, pedúnculo diferenciado, ancho y espeso, de bordes paralelos rectos o cóncavos y base cóncava. El subtipo 2c presenta limbo triangular mediano y convexo, aletas entrantes agudas, pedúnculo diferenciado, de bordes divergentes cóncavos y base cóncava (atenuada o escotada). El subtipo $2 \mathrm{~d}$ se distingue por el limbo triangular alargado y recto, aletas entrantes agudas, pedúnculo diferenciado de bordes paralelos cóncavos y base cóncava (atenuada o escotada). Este subtipo fue datado en el enterratorio Rawson en $270 \pm$ 60 años AP (edad no calibrada) (Gómez Otero 2011). La proporción de cada subtipo varía entre las áreas: el más abundante en CN y MCN es el 2c (49\%) y en VCH
BNorte 151 (de sílice); LAzu 122 (de xilópalo) y LAzu $132,134,135$ y 141 (de calcedonia). En VCH hay una de xilópalo -Raw 61- y en MCN dos de obsidiana tipo SI: Chenque 19A y Suc.Montenegro 1/14 (Figura 3). Las más reactivadas fueron las de calcedonia (40\%). Los cabezales fracturados presentan similar frecuencia en las tres áreas: $9 \%$ en CN y en VCH y $8 \%$ en MCN; los "transformados" solo se registraron en $\mathrm{MCN}(16 \%)$ y en $\mathrm{CN}(2 \%)$.

\section{Variables métricas del total de la pieza}

En cuanto a las diferencias métricas entre las áreas: las puntas de $\mathrm{CN}$ presentan el rango de variación más amplio en todas las variables, mientras que las de $\mathrm{VCH}$ y MCN muestran diferencias equivalentes entre los valores máximos y mínimos (Tabla 4). Respecto de los valores promedios para las tres áreas, en ancho son similares (entre $\bar{X} 14,1 \mathrm{~mm}$ y $\bar{X} 13,5 \mathrm{~mm}$ ); en longitud, los más altos son los del $\mathrm{VCH}(\overline{\mathrm{X}} 23,3 \mathrm{~mm})$, los menores los de MCN ( $\bar{X} 20,8 \mathrm{~mm})$, mientras que el espesor más elevado fue registrado en $\mathrm{CN}(\overline{\mathrm{X}} 3,4 \mathrm{~mm})$ y el inferior en $\mathrm{VCH}(\overline{\mathrm{X}} 2,9 \mathrm{~mm})$ (Tabla 4).

\section{Variables métricas y análisis estadístico del pedúnculo}

Los pedúnculos de $\mathrm{CN}$ y $\mathrm{MCN}$ presentan los valores más altos en longitud, ancho de la raíz y de la base. Las tres áreas muestran valores parejos en 
Tabla 4. Largo, ancho y espesor de las piezas completas.

Length, width and thickness of the whole points.

\begin{tabular}{cccccccccc}
\hline \multirow{2}{*}{ Variables } & \multicolumn{3}{c}{ CN } & \multicolumn{3}{c}{ VCH } & \multicolumn{3}{c}{ MCN } \\
\cline { 2 - 10 } & Máx & Mín & Prom & Máx & Mín & Prom & Máx & Mín & Prom \\
\hline Largo & 34,4 & 14,1 & 21,2 & 33,1 & 15,4 & 23,3 & 28,8 & 12,8 & 20,8 \\
\hline Ancho & 24,8 & 10.6 & 14,1 & 18,4 & 10,5 & 14,2 & 19 & 8,8 & 13,5 \\
\hline Espesor & 4,5 & 1,7 & 3,4 & 4,08 & 2,2 & 2,9 & 4,28 & 2 & 3,2 \\
\hline
\end{tabular}

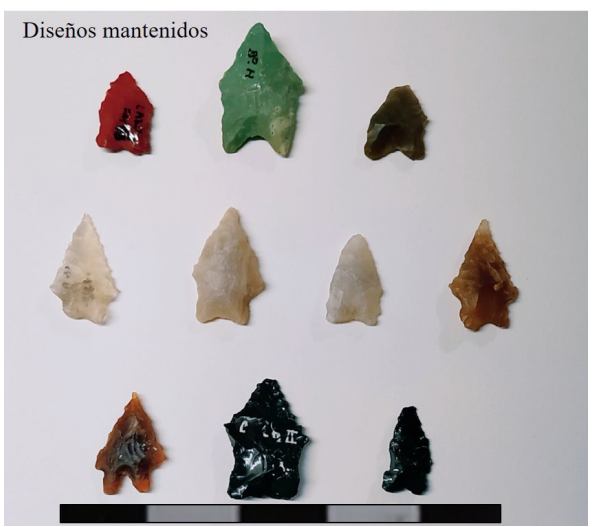

Figura 3. Puntas de proyectil: diseños mantenidos. Projectile points: resharpened points.

Tabla 5. Variables métricas del pedúnculo (máximas, mínimas y promediadas).

Metric variables of the stem (maximum, minimum, and average).

\begin{tabular}{|c|c|c|c|c|c|c|c|c|c|c|c|c|c|c|c|}
\hline \multirow{2}{*}{ Variables } & \multicolumn{3}{|c|}{ Largo } & \multicolumn{3}{|c|}{ Ancho Raíz } & \multicolumn{3}{|c|}{ Espesor Raíz } & \multicolumn{3}{|c|}{ Ancho Base } & \multicolumn{3}{|c|}{ Espesor Base } \\
\hline & Mín & Máx & Prom & Mín & Máx & Prom & Mín & Máx & Prom & Mín & Máx & Prom & Mín & Máx & Prom \\
\hline $\mathrm{CN}$ & 3,67 & 12,7 & 5,22 & 5,26 & 14,53 & 8,6 & 2,53 & 5,67 & 3,3 & 6 & 13,1 & 9,3 & 1,13 & 3,6 & 2,1 \\
\hline $\mathrm{VCH}$ & 3,05 & 8,53 & 5,73 & 6,16 & 9,96 & 7,9 & 2,24 & 3,67 & 2,9 & 6,81 & 10,3 & 8,64 & 1,02 & 3,3 & 2,1 \\
\hline $\mathrm{MCN}$ & 2,6 & 13,07 & 5,6 & 5,2 & 11,45 & 8,2 & 2,07 & 4,09 & 3,09 & 1,66 & 13,4 & 8,73 & 1,37 & 10,24 & 2,4 \\
\hline
\end{tabular}

Por su parte, el análisis de la varianza ANOVA de un factor efectuado a las piezas con pedúnculo no fracturado (93\%), mostró diferencias estadísticamente significativas solo para el espesor de la raíz $(\mathrm{F}=3,14$; $\mathrm{p}=0,04)$. En cuanto al ACP, los resultados indican que los dos primeros componentes -CP1 y CP2- explican el $82,9 \%$ de la varianza de la muestra. En el CP1 (63,3\% de la varianza), los atributos definitorios fueron el ancho de la raíz y el ancho de la base; en el CP2 $(19,6 \%)$ el más influyente fue el largo del pedúnculo (Tabla 6). A partir de estos dos componentes se realizó un gráfico de dispersión para ilustrar las relaciones de similitud entre las puntas (Figura 3). Se observó la

Tabla 6. Variables métricas del pedúnculo (máximas, mínimas y promediadas).

Metric variables of the stem (maximum, minimum, and average).

\begin{tabular}{ccc}
\hline Variables & CP1 $(63,3 \%)$ & CP2 (19,6\%) \\
\hline Largo del pedúnculo & 0,484 & 0,713 \\
Ancho de la raíz & 0,571 & $-0,010$ \\
Espesor de la raíz & 0,153 & 0,070 \\
Ancho de la base & 0,675 & $-0,497$ \\
Espesor de la base & 0,037 & 0,488 \\
\hline
\end{tabular}

superposición parcial de la mayoría de los ejemplares de las tres áreas, aunque hay mayor dispersión de las puntas de $\mathrm{CN}$ y de MCN (Figura 3). Tres cabezales -BNorte $151(\mathrm{CN})$, CChenque 19A (MCN y AC 180 (MCN- se comportan como "outliers", diferenciándose por los valores del espesor de la raíz y el ancho de la base (Figura 3). Los dos primeros presentan los valores más altos y el tercero los más bajos. Esto refuerza el resultado del test ANOVA para la variable "espesor de la raíz".

\section{Materias Primas}

Todas las puntas fueron manufacturadas sobre rocas de calidad muy buena a excelente. La diferencia radica en el número de variedades litológicas: en la $\mathrm{CN}$ se usaron cinco (basalto, sílices, calcedonias, xilópalos y obsidianas), mientras que en $\mathrm{VCH}$ y en $\mathrm{MCN}$ solo tres (Tabla 7). En todas las áreas predominan las puntas de calcedonia (entre 42 y 59\%), seguidas por las de sílices que en $\mathrm{VCH}$ alcanzan el $43 \%$, en $\mathrm{CN}$ el $26 \%$ y en MCN el 16\% (Tabla 7). En cuanto a la distribución y frecuencia de las litologías usadas, las puntas de basalto solo fueron registradas en $\mathrm{CN}(14 \%)$, las de xilópalos en 
$\mathrm{CN}(14 \%)$ y en $\mathrm{VCH}(5 \%)$ y las de obsidianas en $\mathrm{MCN}$ (28\%) y en CN (2\%). Las puntas de obsidianas de CN son similares macroscópicamente a artefactos y nódulos de la fuente T/SCI, ubicada a $180 \mathrm{~km}$ hacia el oeste. Por su parte, las de Sucesión Montenegro y Cañadón de los Fósiles (MCN) son como los de la fuente SI, que se encuentra a 5 y $50 \mathrm{~km}$ respectivamente de esos sitios (Gómez Otero y Stern 2005; Stern et al. 2000) (Figura 1). La relación entre los subtipos y las materias primas es la siguiente: del subtipo $2 \mathrm{a}(\mathrm{n}=10)$, cinco son de sílices y cuatro de calcedonias; el único ejemplar de obsidianaes de MCN; del subtipo de $2 \mathrm{c}(\mathrm{n}=21)$, ocho son de calcedonias, cuatro de sílices y xilópalos respectivamente; hay dos de basalto en $\mathrm{CN}$ y tres de obsidiana en MCN. Entre las del subtipo $2 \mathrm{~d}(\mathrm{n}=14)$, ocho son de calcedonia, una de sílice en cada área, dos de basalto y una de obsidiana en $\mathrm{CN}$.

\section{Discusión y Conclusiones}

El análisis de las 103 puntas mostró variabilidad morfológica interna pero neto predominio en las tres áreas de tres subtipos básicos definidos por Gómez Otero et al. (2011) como 2a, 2c y 2d (Figura 2). En lo que respecta al pedúnculo, las dos pruebas estadísticas -ANOVA y ACP- no revelaron variaciones métricas significativas. Las variables técnicas tampoco dan cuenta de patrones distintos en las tres áreas, ya que casi todas las puntas fueron elaboradas sobre lascas formatizadas por microrretoque profundo y microrretoque marginal, preferentemente irregular. En líneas generales, todas estas características señalan la existencia de rasgos morfológicos, técnicos y métricos compartidos entre las áreas.

No obstante, la diferente distribución de los subtipos por área sugiere situaciones particulares. Por ejemplo, el 2 a presenta similar frecuencia en $\mathrm{VCH}$ y MCN (26\% y $24 \%$ respectivamente) y también se lo ha identificado en contextos del Holoceno Tardío del norte de Santa Cruz y de Chubut atribuidos al "Complejo Patagoniense" (Aschero 1983; Aschero et al. 2006; Gradin 1980). En Chubut fue registrado en muestras del valle medio-superior del río homónimo (Aschero et al. 1983, 2006; Castro Esnal 2014; entre otros), en la meseta centro-sur (Aguerre et al. 2018; Aschero et al. 2006; Castro Esnal 2014; Gradin y Aschero 1978; entre otros) y en el valle del Río Chico (Castro Esnal 2014). Tan amplia distribución en Patagonia central sugiere que este diseño se habría desarrollado antes que los otros. De hecho, en varios contextos del Holoceno Tardío inicial de la región se encontraron puntas morfológicamente semejantes, aunque de mayor tamaño (Aschero et al. 1983; Gradin 1980; Gradin y Aschero 1978; Gradin et al. 1976). Es probable, entonces, que esta versión más pequeña del mismo modelo se deba al cambio tecnológico que significó la adopción del arco y la flecha, tal como propusieron Gradin (1980) y Aschero (1983). En cuanto al subtipo

Tabla 7. Porcentaje de la varianza que aportan los dos primeros componentes principales.

Percentage of the variance provided by PC1 and PC2.

\begin{tabular}{|c|c|c|c|c|c|c|}
\hline \multirow{2}{*}{\multicolumn{2}{|c|}{ Áreas de estudio y sitios arqueológicos }} & \multicolumn{5}{|c|}{ Materias primas } \\
\hline & & $\mathrm{Ba}$ & Sil & Cal & Xil & $\mathrm{Ob}$ \\
\hline \multirow{12}{*}{ 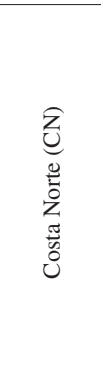 } & Rincón de Elizalde & -- & 1 & 1 & -- & 1 \\
\hline & El Progreso & -- & -- & 1 & -- & -- \\
\hline & La Azucena & 3 & 6 & 14 & 3 & -- \\
\hline & Las Ollas & -- & 1 & 1 & 2 & -- \\
\hline & Fracaso & -- & -- & -- & 1 & -- \\
\hline & Punta Delgada & 1 & -- & -- & -- & -- \\
\hline & Ea. La Laurita & 1 & -- & -- & -- & -- \\
\hline & Caleta Valdés & 1 & -- & -- & -- & -- \\
\hline & Bajo Norte & -- & 2 & 1 & -- & -- \\
\hline & El Golfito & -- & 1 & -- & -- & -- \\
\hline & Bahía Cracker & -- & -- & -- & -- & 1 \\
\hline & Total & $6(14 \%)$ & $11(26 \%)$ & $18(42 \%)$ & $6(14 \%)$ & $2(4 \%)$ \\
\hline \multirow{5}{*}{ 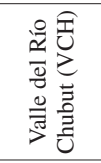 } & Rawson & -- & 1 & 5 & 1 & -- \\
\hline & Los Altares & -- & 4 & 3 & & -- \\
\hline & Laguna Bombilla & -- & 5 & 2 & & -- \\
\hline & Cabeza de Buey & -- & 1 & 1 & -- & -- \\
\hline & Total & -- & $10(43 \%)$ & $12(52 \%)$ & $1(5 \%)$ & -- \\
\hline \multirow{5}{*}{ 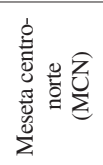 } & Cerro Chenque & -- & -- & -- & -- & 1 \\
\hline & Cañadón de los Fósiles & -- & -- & 1 & -- & -- \\
\hline & Sucesión Montenegro & -- & 1 & 1 & -- & 8 \\
\hline & Puesto Arsenio Balbo & -- & 5 & 20 & -- & -- \\
\hline & Total & -- & $6(16 \%)$ & $22(59 \%)$ & -- & $9(25 \%)$ \\
\hline
\end{tabular}


2c, su alto predominio en $\mathrm{CN}$ y $\mathrm{MCN}$ (49\%) y bajo en VCH (17\%) sugiere relaciones más estrechas entre el litoral y la meseta centro norte que entre el litoral y el valle. No se puede afirmar aún cuál de las dos áreas $(\mathrm{CN}$ y $\mathrm{MCN}$ ) fue el ámbito donde se originó esta variedad morfológica. Por su parte, la proporción relativamente importante del subtipo $2 \mathrm{~d}$ en CN (24\%) pero inferior en las otras áreas, sugiere un desarrollo local en la costa norte. Por último, los porcentajes parejos de los tres subtipos más el $2 \mathrm{f}$ en $\mathrm{VCH}$ indicaría que el río habría funcionado como vector o corredor de comunicación entre el litoral y distintos tramos de su valle, por donde circularon diseños de distintas zonas.

Respecto de la selección de las materias primas, excepto en VCH donde las sílices son locales y su uso en las puntas alcanzó un 43\%, no se observó vinculación con la abundancia local de las rocas de mejor calidad en cada área. En $\mathrm{CN}$ el basalto (altamente disponible) solo se registró en $14 \%$ de las puntas, lo que contrasta con su aprovechamiento mayoritario para otros grupos tipológicos (Banegas 2016). En MCN, donde se encuentran las fuentes de obsidiana SI y T/SCI, los cabezales de esta roca promediaron el $11 \%$, excepto en Sucesión Montenegro (24\%), a cinco kilómetros de la fuente SI. Esta escasa representación de las obsidianas fue asimismo corroborada en diversos sitios de $\mathrm{CN}$ y en la desembocadura del Río Chubut donde la media general no sobrepasó el 3\% (Gómez Otero y Stern 2005). De las dos fuentes conocidas para la provincia del Chubut, SI es la que muestra mayor dispersión espacial, no solo en estas tres áreas sino fuera de ellas ${ }^{2}$, mientras que T/SCI fue identificada geoquímicamente en $\mathrm{CN}$ y en $\mathrm{MCN}$ pero no en el valle inferior (Gómez Otero y Stern 2005; Stern et al. 2000). Sin embargo, en el sitio Cinco Esquinas, a $10 \mathrm{~km}$ al oeste de Rawson, se registraron artefactos -actualmente en proceso de análisis geoquímico-muy similares macroscópicamente a los nódulos de T/SCI (Gómez Otero et al. 2010). La representación de todas las etapas de la producción lítica en los distintos conjuntos artefactuales de la costa norte y el valle inferior indica el ingreso de nódulos enteros (Gómez Otero y Stern 2005).

Los xilópalos también mostraron baja proporción, incluso en $\mathrm{VCH}(5 \%)$ donde se encuentra el bosque petrificado cercano al dique Ameghino. Esto podría estar relacionado con su estructura interna, por ejemplo, la presencia de nudos que dificultarían la talla bifacial (Banegas et al. 2015). Es muy probable que algunas puntas provengan de esa fuente primaria, pero también pudo haberse dado el aprovechamiento oportunista de fuentes secundarias (bloques, rodados o tabletas de troncos fósiles) disponibles en el fondo de cañadones o sobre terrazas. La ampliación del estudio de nódulos y artefactos de xilópalo mediante MEB y EDAX (Banegas et al. 2016), permitirá cotejar estas hipótesis.
En contraste, a pesar de su baja disponibilidad o localización alejada de los sitios aquí analizados, la calcedonia fue la roca más utilizada en las tres áreas, llegando a ocupar alrededor del 50\%. Una explicación para la selección de esta materia prima podría vincularse con su tenacidad o resistencia a las fracturas. Al respecto, un estudio de Ratto y Belardi (1996) sobre las propiedades estructurales de las rocas usadas en Cerro Castillo señala que la calcedonia es la única con tenacidad elevada, mientras que basaltos, sílices y obsidianas muestran valores medios a bajos (Ratto y Belardi 1996:Tablas 1-2). Las materias primas también pueden ser elegidas por otro tipo de razones; por ejemplo, atributos estéticos. De las cinco rocas identificadas, excepto el basalto que es opaco, las demás presentan colores vistosos y brillantes. En este sentido, la calcedonia podría haber sido la más seleccionada no solo por su calidad superior para la talla, sino por razones de comunicación visual o de prestigio, tal como se ha propuesto para otros casos (Boivin y Owoc 2004; Colombo y Flegenheimer 2013; Flegenheimer y Bayón 1999; Taçon 1991). Al respecto, el incremento estadísticamente significativo que Banegas y Goye (2015) determinaron para la frecuencia de artefactos de calcedonia en $\mathrm{CN}$ y el valle inferior del río Chubut a partir del Holoceno Tardío final, sugiere una utilización más intensiva de esta roca y el cambio hacia una estrategia tecnológica conservada (Nelson 1991). Algunos cabezales podrían haberse elaborado con las calcedonias de la fuente de Arroyo Verde, en el sector más septentrional de la costa norte (Figura 1).

La presencia de puntas de materias primas -obsidianas, calcedonias y xilópalos- cuyas fuentes tienen una distribución espacialmente restringida y dispar entre las áreas, señala contactos regulares entre ellas. Esto coincide con el registro de los tres subtipos mayoritarios en las tres áreas estudiadas. Estas relaciones intrarregionales en el Holoceno Tardío tienen sustento a través de otras líneas de evidencia. Por ejemplo, piezas cerámicas halladas en $\mathrm{CN}$ y MCN presentan rasgos litológicos, tecno-morfológicos y decorativos típicos de dos tradiciones culturales del centro-sur de Chile, como los estilos Pitrén y Valdivia (Schuster 2015). A su vez, en enterratorios múltiples del valle inferior del Río Chubut, entre ellos el sitio Rawson aquí tratado, se registraron cuentas de rocas ornamentales no locales como malaquitas, turquesas y serpentina, y también un hacha ceremonial de bronce como las de la cultura Santamariana del Noroeste argentino (Gómez Otero 2011). Por su parte, la amplia representación de los subtipos 2c y $2 \mathrm{~d}$ en CN y MCN -probablemente originados en alguna de esas dos áreas- podría estar vinculado con un proceso de regionalización y de reafirmación de rasgos identitarios de los grupos, de manera similar a lo que Martínez et 
al. (2017) plantearon para las ocupaciones tardías de la desembocadura del Río Colorado. En este respecto y en escala más amplia -actual provincia de Chubuty para tiempos posteriores a $1.500-1.000 \mathrm{AP}$ se ha propuesto la ocurrencia de cambios culturales tales como diversificación tecnológica, aumento en la complejidad social e incremento en los contactos intra y extrarregionales (Gómez Otero y Bellelli 2006). En esos contactos, directos o indirectos, se habrían intercambiado materias primas, bienes, conocimientos técnicos, creencias y genes.

A modo de conclusión, este abordaje metodológico que combinó variables morfométricas, técnicas y litológicas para evaluar la diversidad de puntas de proyectil pequeñas, sumó elementos de juicio para discutir la dinámica de las interacciones sociales en tres ambientes contiguos de Patagonia central en momentos finales del Holoceno Tardío.

Agradecimientos: Al Sr. Anselmo Cadene por permitirnos realizar el análisis de su colección particular. También se agradece a la editora de la revista y a los tres evaluadores anónimos cuyos comentarios y sugerencias significaron un valioso aporte. Este trabajo contó financiamiento del CONICET (PIP 6470 y PIP 1140100100210), ambos dirigidos por Gómez Otero.

\section{Referencias Citadas}

Aguerre, A. J. Andrieu y N. Iantanos 2018. Arqueología en Río Mayo, sudoeste del Chubut. Excavación en el Alero Dásovich: resultados preliminares. Intersecciones en Antropología 18:5565 .

Alberti, J. y M. Cardillo 2016. Análisis morfométrico y tecnológico de artefactos bifaciales. Un caso de estudio del golfo San Matías (provincia de Río Negro, Argentina). Chungara Revista de Antropología Chilena 48 (1):39-52.

Ardolino, A.A. 1981. El vulcanismo cenozoico del borde suroccidental de la meseta de Somún Curá, provincia del Chubut. Actas del $8^{\circ}$ Congreso Geológico Argentino, Actas 1: 65 y 3:7-23, Asociación Geológica Argentina, San Luis.

Aschero, C.A. 1975a. Secuencia arqueológica del Alero de las Manos Pintadas-Las Pulgas, Departamento de Río Senguer, Chubut. Relaciones de la Sociedad Argentina de Antropología (N.S.) IX:87-209.

Aschero, C. 1975b, Rev. 1983. Ensayo para una clasificación morfológica de artefactos líticos aplicada a estudios tipológicos comparativos. Informe presentado al CONICET, Buenos Aires.

Aschero, C.A. 1983. La secuencia de Piedra Parada a través de las campañas 1979-1981: consideraciones finales. En Arqueología del Chubut. El Valle de Piedra Parada, editado por C. Aschero, C. Perez de Micou, Cecilia, M. Onetto, C. Bellelli, L. Nacuzi, Lidia y A. Fisher, pp. 91-103. Gobierno de la Provincia del Chubut, Serie Humanidades, Rawson.

Aschero, C.A.1988. De punta a punta: producción y diseño en puntas de proyectil precerámicas de la Puna Argentina En Precirculados de las Ponencias Científicas presentadas a los Simposios del IX Congreso Nacional de Arqueología Argentina, p. 15. Facultad de Filosofía y Letras, Universidad de Buenos Aires, Buenos Aires.

Aschero, C.A., C. Bellelli, C. Fernandez Lannot, A. Fisher, M.V. Fontanella, J. Gómez Otero y C. Pérez De Micou 2006. Un análisis tipológico y técnico-morfológico de siete sitios del complejo patagoniense. En El Modo de Hacer las Cosas. Artefactos y Ecofactos en Arqueología, editado por C. Pérez de Micou, pp. 21-34. Facultad de Filosofía y Letras, Universidad de Buenos Aires, Buenos Aires.

Aschero, C., C. Bellelli y M.V. Fontanella 1983-85. La industria lítica en la secuencia arqueológica de Chacra Briones (Dique Ameghino - Chubut): excavaciones de O. F. A. Menghin, 1956-59. Cuadernos del Instituto Nacional de Antropología

\section{0:319-338.}

Aschero, C., S. Hocsman y N. Ratto 2011. Las puntas de proyectil "en mandorla" de Inca Cueva 7: Caracterización tipológica e historia de vida (Puna de Jujuy, Argentina). Estudios Atacameños 41:5-28.

Aschero, C. y J.G. Martínez 2001. Técnicas de caza en Antofagasta de la Sierra, Puna Meridional Argentina. Relaciones de la Sociedad Argentina de Antropología XXVI:215-242.

Aschero, C., C. Pérez de Micou, M. Onetto, C. Bellelli, L. Nacuzzi y A. Fisher 1983. Arqueología del Chubut. El Valle de Piedra Parada. Gobierno de la Provincia del Chubut, Serie Humanidades, Rawson.

Bagolini, B. 1968. Ricerche sulle dimensioni dei manufatti litici non ritoccati. Annoli dell'Universitàdi Ferrara I 10, Ferrara.

Banegas, A. 2016. La Organización de la Tecnología Lítica y el Uso del Espacio en la Costa Centro-Septentrional de Patagonia. Tesis doctoral inédita, Facultad de Ciencias Naturales y Museo, Universidad Nacional de La Plata, La Plata.

Banegas, A., J. Gómez Otero, M. Goye y N. Ratto 2014. Cabezales líticos del Holoceno tardío en Patagonia meridional: diseños y asignación funcional. Magallania 42 (2):155-174.

Banegas A. y M. Goye 2015. Spatial and temporal variability in the use of lithic raw materials for flaked stone technology in the northeast of Chubut Province (North Patagonia) during Late Holocene. En Archaeology of coastal hunter-gatherer occupations in the Southern Cone, editado por P. Ambrústolo y M.A. Zubimendi. Quaternary International 373:55-62.

Banegas, A., S. Goye y J. Gómez Otero 2015. Caracterización regional de recursos líticos en el nordeste de la provincia del Chubut (Argentina). En Materias Primas Líticas en Patagonia Localización, Circulación y Métodos de Estudio de las Fuentes de Rocas de la Patagonia Argentino-Chilena, editado por J. Alberti J y V. Fernandez. Intersecciones en Antropología, Dossier 2:39-50.

Banegas, A., R. Pujana y J. Gómez Otero 2016. Caracterización tecnológica de xilópalos de la costa centro-septentrional de Patagonia: tendencias temporales y potenciales fuentes de aprovisionamiento. En Arqueología de Patagonia: De Mar a Mar, pp. 415-422. CIEP, Coyhaique.

Beeskow, A.M., H.F. Del Valle y C.M. Rostagno 1987. Los Sistemas Fisiográficos de La Región Árida y Semiárida de la Provincia del Chubut. Delegación Regional Patagonia, SECyT, Puerto Madryn. 
Belardi, J.B. 1996. Cuevas, aleros, distribuciones y poblamiento. En Arqueología: Sólo Patagonia, editado por J. Gómez Otero, pp. 43-48. Centro Nacional PatagónicoCONICET, Puerto Madryn.

Bellelli, C.1983. Sitio Campo Moncada 2. En Arqueología del Chubut. El Valle de Piedra Parada, editado por C. Aschero, C. Perez de Micou, Cecilia, M. Onetto, C. Bellelli, L. Nacuzi, Lidia y A. Fisher, pp. 31-42. Gobierno de la Provincia del Chubut, Serie Humanidades, Rawson.

Bellelli, C., M. Carballido Calatayud y Ch. Stern 2018. Obsidianas en el bosque: Determinación geoquímica de artefactos arqueológicos del S-O de Río Negro y N-O de Chubut (Patagonia Argentina). Chungara Revista de Antropología Chilena 50 (2):201-216.

Bettinger, R.L. y J. Eerkens 1999. Point typologies, cultural transmission, and the spread of bow-and-arrow technology in the Prehistoric Great Basin. American Antiquity 64 (2):231242.

Binford, L. 1973. Interassemblage variability: The Mousterian and the 'Functional Argument'. En Explanation of Cultural Change: Models in Prehistory, editado por C. Renfrew, pp. 227-254. Duckworth, Londres.

Binford, L.R. 1979. Organization and formation processes: looking at curated technologies. Journal of Anthropological Research 35:255-273.

Bird, J. 1988. Viajes y Arqueología en Chile Austral. Editado por J. Hyslop. Ediciones de la Universidad de Magallanes, Punta Arenas.

Boivin, N. y M.A. Owoc 2004. Soils, Stones and Symbols. Cultural Perceptions of the Mineral World. UCL Press, Londres.

Bonorino, G.F. y M.E. Teruggi 1952. Léxico Sedimentológico. Museo Argentino de Ciencias Naturales Bernardino Rivadavia, Buenos Aires.

Boschín, M.T. 2009. Tierra de Hechiceros. Arte Indígena de Patagonia Septentrional Argentina. Ediciones Universidad de Salamanca, Servicio de Publicaciones de la Universidad de Córdoba, Córdoba.

Boschín, M.T. y G. Massaferro 2014. La obsidiana: una señal geoarqueológica del alcance de las relaciones sociales en Patagonia pre y post-hispánica. En Arqueología Precolombina en Cuba y Argentina: Esbozos desde la Periferia, editado por O. Hernández de Lara y A.M. Rocchietti, pp. 227-258. Aspha Ediciones, Buenos Aires.

Brea, M., S. Matheos, A. Zucol, A. Iglesias, M.S. Raigemborn y M. Prámparo 2006. Estudios paleobotánicos en la secuencia daniana de la localidad fosilifera del "Bosque petrificado Ameghino" (Chubut, Argentina). Actas del IX Congreso Argentino de Paleontología y Bioestratigrafia, 139-146. Actas 33, Córdoba.

Buchanan B., E. Johnson, R.E. Staruss y P.J. Lewis 2007. A morphometric approach to asseinng late Paleoindian projectile point variability on the Southern High Plains. Plains Antrhopologist 52:279-299.

Castro Esnal, A. 2014. Camino y Piedra. Rutas Indígenas y Arqueología en la Provincia del Chubut. Fundación de Historia Natural Félix de Azara, Buenos Aires.

Cardich, A., L.A. Cardich y A. Hajduck 1973. Secuencia arqueológica y cronológica radiocarbónica de la cueva 3 de los Toldos (Santa Cruz,
Argentina). Relaciones de la Sociedad Argentina de Antropología (NS) VII:85-123.

Charlin, J. y R. González-Jose 2012. Size and shape variation in Late Holocene projectile points of southern Patagonia. A geometric morphometric study. American Antiquity 77 (2):221-242

Colombo, M. y N. Flegenheimer 2013. La elección de rocas de colores por los pobladores tempranos de las sierras de Lobería (Buenos Aires, Argentina). Nuevas consideraciones desde las canteras. Boletín del Museo de Arte Precolombino de Chile 18 (1):125-137. Santiago.

Crivelli Montero, E., D.E. Curzio y M.J. Silveira 1993. La estratigrafía de la Cueva Traful I (provincia de Neuquén). Praehistoria 1:9-161.

Dibble, H.L. 1987. The interpretation of Middle Paleolithic Scraper Morphology. American Antiquity 52:109-117.

Fernández, J. 1988-1990. La cueva de Haichol. Arqueología de los pinares cordilleranos del Neuquén. Anales de Arqueología y Etnología 43-45 (1-III): 1-740. Universidad Nacional de Cuyo, Mendoza.

Flegenheimer, N. y C. Bayón 1999. Abastecimiento temprano de rocas en sitios pampeanos tempranos: recolectando colores. En Los Tres Reinos: Prácticas de Recolección en el Cono Sur de América, editado por C. Aschero, M.A. Korstanje y P.M. Vuoto, pp. 95-107. Instituto de Arqueología y Museo, Facultad de Ciencias Naturales e Instituto Miguel Lillo, Tucumán.

Flenniken, J. y A. Raymond 1986. Morphological projectile point typology: replication, experimentation and technological analysis. American Antiquity 51 (3):603-614.

Franco, N.V. y E. Aragón 2004. Variabilidad en fuentes secundarias de aprovisionamiento lítico: El caso del sur del lago Argentino (Santa Cruz, Argentina). Estudios Atacameños 28:71-85

Franco, N.V., A. Castro, M. Cardillo y J. Charlin 2009. La importancia de las variables morfológicas, métricas y de microdesgaste para evaluar las diferencias en diseños de puntas de proyectil bifaciales pedunculadas: un ejemplo del sur de Patagonia continental. Magallania 37 (1):99-112.

Franco, N.V., J. Gómez Otero, G. Guráieb, M.S. Goye y N. Cirigliano 2010. Variaciones espaciales en diseños de puntas pedunculadas medianas en Patagonia argentina: una nueva aproximación. Actas del XVIII CNAA, Arqueología Argentina en el Bicentenario de la Revolución de Mayo T.1, pp. 281-286. Facultad de Filosofía y Letras de la Universidad Nacional de Cuyo e INCIHUSA-CONICET, Mendoza.

Gómez Otero, J. 2006. Dieta, Uso del Espacio y Evolución en Poblaciones Cazadoras-Recolectoras de la Costa CentroSeptentrional de Patagonia durante el Holoceno Medio y Tardio. Tesis doctoral inédita, Facultad de Filosofía y Letras, Universidad de Buenos Aires, Buenos Aires.

Gómez Otero, J. 2008. Arqueología de la costa centroseptentrional de Patagonia. En Arqueología de la Patagonia: perspectivas para la conservación, editado por I. Cruz y M.S. Caracotche, pp. 72-80. Universidad Nacional de la Patagonia Austral, Río Gallegos.

Gómez Otero, J. 2011. La importancia de rescatar los enterratorios humanos en riesgo: experiencias en el nordeste de la provincia del Chubut. Cazadores-Recolectores del Cono Sur 5:15-33.

Gómez Otero, J., V. Alric y R. Taylor 1996. Una nueva forma cerámica del Chubut: análisis mineralógicos y experiencias de reproducción. En Arqueología: sólo Patagonia, editado por J. 
Gómez Otero, pp. 349-358. Centro Nacional PatagónicoCONICET, Puerto Madryn.

Gómez Otero, J., A. Banegas, L. Caruso Fermé, M. Goye, G. Millán V. Schuster, A. Svoboda y N. Weiler 2017. Los antiguos pobladores humanos: arqueología de la bajada Colombo. En Reserva de Vida Silvestre San Pablo de Valdés: 10 años conservando el patrimonio natural y cultural de la Península Valdés, Patagonia Argentina, editado por D. Udrizar Sauthier, G. Pazos y A. Arias, pp. 228-247. Fundación Vida Silvestre Argentina, Buenos Aires.

Gómez Otero, J., J.B. Belardi, A. Súnico y R. Taylor 1999. Arqueología de cazadores recolectores en Península Valdés, costa central de Patagonia: primeros resultados. En Soplando en el Viento.. Actas de Las Terceras Jornadas de Arqueología de la Patagonia, pp. 393-417. Universidad Nacional del Comahue, Neuquén.

Gómez Otero, J. y C. Bellelli 2006. La Patagonia central poblamientos y culturas en el área de Chubut. En Patagonia Total. Antártida e Islas Malvinas. Primera parte: Historias de la Patagonia. Sociedades y Espacios en el Tiempo, coordinado por S. Bandieri y G. Blanco, pp. 27-51. Alfa Literario-Patagonia Argentina/Barcel Baires Ediciones, Buenos Aires.

Gómez Otero, J. y S. Dahinten 1997-98. Costumbres funerarias y esqueletos humanos: variabilidad y poblamiento en la costa nordeste de la provincia del Chubut (Patagonia argentina) Relaciones de la Sociedad Argentina de Antropología XXII:101-124.

Gómez Otero, J., E.J. Moreno y V. Schuster 2010. Ocupaciones tardías en el valle inferior del río Chubut: primeros resultados del sitio Cinco Esquinas. En Arqueología Argentina en el Bicentenario de la Revolución de Mayo, editado por J.R. Bárcena y H. Chiavazza, T.V, pp. 1917-1922. Facultad de Filosofía y Letras de la Universidad Nacional de Cuyo e INCIHUSA-CONICET, Mendoza.

Gómez Otero, J. y Ch. Stern 2005. Circulación, intercambio y uso de obsidianas en la costa de la provincia del Chubut (Patagonia, Argentina) durante el Holoceno Tardío. Intersecciones en Antropología 6:93-108

Goye, M.S. y N. Weiler 2017. Variaciones del nivel marino y estrategias humanas durante el Holoceno tardío: el caso de la Localidad arqueológica Barranca Norte (Bahía Engaño, Prov. del Chubut). Libro de resúmenes de las X Jornadas de Arqueología de la Patagonia, pp. 27. IDEAus-CONICET, Puerto Madryn.

Gradin, C.J. 1980. Secuencias radiocarbónica del sur de la Patagonia Argentina. Relaciones de la Sociedad Argentina de Antropología (NS) XIV (1):177-194.

Gradin, C.J. 1985. Área de los cazadores meridionales (PampaPatagonia). En Arte Rupestre de la Argentina, editado por J. Schobinger y C.J. Gradin. Ediciones Encuentro, Madrid.

Gradin, C.J. y C. Aschero 1978. Cuatro fechas radiocarbónicas para el Alero del Cañadón de las Manos Pintadas (Las Pulgas, Prov. de Chubut). Relaciones de la Sociedad Argentina de Antropología XII (NS) 245-248.

Gradin, C., C. Aschero y A. M Aguerre 1976. Investigaciones arqueológicas en la Cueva de las Manos, estancia Alto Río Pinturas (provincia de Santa Cruz). Relaciones de la Sociedad Argentina de Antropología X:201-250. Buenos Aires.

Ichazo, G.J. 1994. Análisis de la dinámica geomorfológica determinante del diseño actual del río en el valle inferior del río Chubut (VIRCH). En Guía de Campo de la VII Reunión de Campo del CADINQUA, pp. 4648, Centro Nacional Patagónico, Puerto Madryn.

Haller, M. 1981. Descripción Geológica de la Hoja 43h "Puerto Madryn”, Provincia del Chubut. Boletín $N^{\circ} 184$, Servicio Geológico Nacional, Buenos Aires.
Hammer, O., D.A.T. Harper y P.D. Ryan 2001. Past: Paleontological statistics software package for education and data analysis. Paleontología Electrónica 4 (1):1-9.

Knetch, H. 1997. Projectile Technology. Plenum Press, New York \& London.

Kuhn, S. 1990. A geometric index of reduction for unifacial stone tools. Journal of Archaeological Science 17:583-593.

Malvicini, L. y E. Llambías 1974. Geología y génesis del depósito de manganeso Arroyo Verde, provincia del Chubut, Argentina. Actas del $5^{\circ}$ Congreso Geológico Argentino T.II, pp. 185-202.

Manly, B.F. 1994. Multivariate Statistical Methods (2nd Edition), Chapman and Hall, London.

Martínez, G. (ed.) 2017. Arqueología de Cazadores-Recolectores del Curso Inferior del Río Colorado (Provincia de Buenos Aires, Argentina). Aportes al Conocimiento de las Ocupaciones Humanas Pampeano-Patagónicas. Serie Monográfica 6 , INCUAPA-CONICET UNICEN. Olavarría.

Martínez, G., F. Santos Valero, G. Flensborg, N. Carden, L. Stoessel, A. P. Alcaraz y E. Borges Vaz 2017. Was there a process of regionalization during the Late Holocene? Journal of Island \& Coastal Archaeology 12 (1):95-114.

Martínez, J. 2003. Ocupaciones Humanas Tempranas y Tecnología de Caza en la Microrregión de Antofagasta de la Sierra (100007000 AP). Tesis de Doctorado. Facultad de Ciencias Naturales e Instituto Miguel Lillo, Universidad Nacional de Tucumán, San Miguel de Tucumán.

Massaferro, G.I. y M.J. Haller 2000. Texturas de las vetas epitermales del Macizo Norpatagónico. Actas del $5^{\circ}$ Congreso de Mineralogía y Metalogenia, pp. 312-319. La Plata.

Nami, H.G. 1997. Investigaciones actualísticas para discutir aspectos técnicos de los cazadores-recolectores del tardiglacial: el problema Clovis-Cueva Fell. Anales del Instituto de la Patagonia (Serie Ciencias Humanas) 25:151-186.

Nelson, M. 1991.The study of technological organization. En Archaeological Method and Theory, editado por M. Schiffer, vol. 3, pp. 57-100. University of Arizona Press, Tucson.

Odell, G.H. y F. Cowan 1986. Experiments with Spears and Arrows on Animal Targets. Journal of Field Archaeology 13:195-212.

Orquera, L.A. 1987. Advances in the Archaeology of the Pampa and Patagonia. Journal of World Archaeology 1 (4):333-413.

Panza, J.L., L.E. Sacomani, C. Parisi, M.F. Rodríguez y E. Aragón 2002. Hoja Geológica 4366-27. Campamento Villegas. Provincia del Chubut. Escala 1:100.000. Boletín SEGEMAR 330:154.

Prates, L. 2008. Los Indígenas del Río Negro. Un Enfoque Arqueológico. Colección Tesis doctorales, Sociedad Argentina de Antropología, Buenos Aires.

Ratto, N. 2003. Estrategias de Caza y Propiedades del Registro Arqueológico en la Puna de Chaschuil (Departamento Tinogasta, Catamarca). Tesis Doctoral, Facultad de Filosofía y Letras, Universidad de Buenos Aires. Disponible en: http://cambiocultural. homestead.com/ratto.html.

Ratto, N. y J.B. Belardi 1996. Selección y uso de materias primas líticas en la región de Cerro Castillo (Pcia. de Chubut y Río Negro). En Arqueología: Sólo Patagonia, editado por J. Gómez Otero, pp. 411-422. Centro Nacional Patagónico-CONICET, Puerto Madryn.

Schuster, V. 2015. Cerámica arqueológica de la costa, valle y meseta de la provincia del Chubut (Patagonia argentina): estudio comparativo preliminar de la composición de las pastas a través de la petrografía. Intersecciones en Antropología 16 (2):353-366. 
Schuster, V. y G. Massaferro 2017. Arqueología en el valle medio del río Chubut: resultados de los primeros trabajos exploratorios en la localidad Las Chapas, Dpto. Alsina. Libro de resúmenes de las X Jornadas de Arqueología de la Patagonia, p. 126. IDEAusCONICET, Puerto Madryn.

Shott, M. y K.J. Weedman 2007. Measuring reduction in stone tools: An ethnoarchaeological study of Gamo Hidescrapers from Ethiopia. Journal of Archaeological Science 34:1016-1035.

Sokal, R. y J.F Rolf 1995. Biometry: The Principles and Practice of Statistics in Biological Research. 3ra. edición. W.H. Freeman and Company, New York.

Stern, Ch. 2018. Obsidian sources and distribution in Patagonia, southernmost South America. Quaternary International 468:190-205.

Stern, Ch.R., A. Castro Esnal, C. Pérez de Micou, C. Méndez y F. Mena 2013. Circulation of obsidian in Patagonia central-sur (44 y 46-S; Chubut, Argentina, y Aisén, Chile). En Tendencias Teórico-Metodológicas y Casos de Estudio en la Arqueología de la Patagonia, editado por A.F., Zangrando, R. Barberena, A. Gil, G. Neme, M. Giardina, L. Luna, C. Otaola, S. Paulides, L. Salgán y A. Tivoli, pp. 243-250. Altuna Impresores, Mendoza.
Stern, Ch., J. Gómez Otero y J.B. Belardi 2000. Características químicas, fuentes potenciales y distribución de diferentes tipos de obsidianas en el norte de la provincia del Chubut, Patagonia argentina. Anales del Instituto de la Patagonia, Serie Ciencias Humanas 28:275-290.

Svoboda, A. y J. Gómez Otero 2015. Explotación de fauna dulceacuícola en el valle inferior del río Chubut (Patagonia Central) durante el Holoceno Tardío. Intersecciones en Antropología 16:39-52.

Taçon, P.S.C. 1991. The power of stone: symbolic aspects of stone use and tool development in western Arnhem Land, Australia. Antiquity 65 (247):192-207.

Thomas, D.H. 1978. Arrowheads and atlatl darts: how the stones got the shaft. American Antiquity 43:461-472.

Verhart, L.B.M. 1990. Stone Age Bone and antler points as indicators for "Social Territories" in the European Mesolithic. En Contributions to the Mesolitic in Europe, editado por P.M. Vermeersch y P. Van Peer, pp.139-151. Leuven University Press, Leuven.

Wiessner, P. 1983. Style and social information in Kalahari San projectile points. American Antiquity 48 (2):253-276.

\section{Notas}

\footnotetext{
${ }^{1}$ Se trata del PICT 26040-ANPCyT (2009-2011), dirigido por la Dra. Nora Franco.

${ }^{2}$ La fuente SI trascendió ampliamente las áreas aquí tratadas: llegó hasta Aysén (sur de Chile), la meseta de Somuncurá, el
}

bosque cordillerano del norte de Chubut y sur de Río Negro y la costa norte del golfo San Matías (Bellelli et al. 2018; Boschín y Massaferro 2014; Stern et al. 2013; Stern 2018; entre otros). 
